\title{
Evaluation of Core and Surface Body Temperatures, Prevalence, Onset, Duration and Severity of Hot Flashes in Men after Bilateral Orchidectomy for Prostate Cancer
}

\author{
Naseem A. Aziz, Chris F. Heyns \\ Department of Urology, University of Stellenbosch and Tygerberg Hospital, Cape Town, South \\ Africa
}

\begin{abstract}
Objective: To assess the prevalence, onset, duration and severity of hot flashes in men after bilateral orchidectomy (BO) for prostate cancer, to evaluate body temperature changes during hot flashes and to determine whether an elevated temperature within a few days after $\mathrm{BO}$ can be caused by deprivation of androgen.

Materials and Methods: Patients $(\mathrm{n}=101)$ were questioned about the characteristics of their hot flashes after BO for prostate cancer. A subgroup of these men $(\mathrm{n}=17)$ were instructed to record their oral and forehead temperatures during and at fixed intervals between hot flashes daily for 4 weeks.

Results: The mean age was 71.6 years, mean follow-up after BO was 33.2 months. Hot flashes were reported by 87 men $(86 \%)$ with previous spontaneous remission in $9(10 \%)$. The median time between $\mathrm{BO}$ and the onset of hot flashes was 21 days (range 1-730), median number of hot flashes 3 per day (range 1-20), and median duration was 120 seconds (range 5 to 1800). There was no significant difference between median oral $\left(36.4^{\circ} \mathrm{C}\right)$ and forehead $\left(36.0^{\circ} \mathrm{C}\right)$ temperature in the normal state, but during hot flashes the median forehead temperature $\left(37.0^{\circ} \mathrm{C}\right)$ was higher than the oral temperature $\left(36.5^{\circ} \mathrm{C}\right)(\mathrm{p}=0.0004)$. Both median oral and forehead temperatures were higher during hot flashes $\left(36.5^{\circ} \mathrm{C}\right.$ and $\left.37.0^{\circ} \mathrm{C}\right)$ than in the normal state $\left(36.4^{\circ} \mathrm{C}\right.$ and $36.0^{\circ} \mathrm{C}$, respectively) $\left(\mathrm{p}<0.0001\right.$ ). During hot flashes, the oral temperature was $38^{\circ} \mathrm{C}$ to $40^{\circ} \mathrm{C}$ in only $3.2 \%$ of 593 readings in 17 patients.

Conclusions: The median oral and forehead temperatures are higher during hot flashes than in normal periods. Oral temperature elevation $>38^{\circ} \mathrm{C}$ within days after a $\mathrm{BO}$ is unlikely to be the result of androgen deprivation alone.
\end{abstract}

Key words: prostate cancer; orchidectomy; androgen; hot flashes

Int Braz J Urol. 2008; 34:15-22

\section{INTRODUCTION}

Hot flashes are common in men with prostate cancer undergoing androgen deprivation therapy (ADT) - about 40-80\% suffer hot flashes and 30$40 \%$ report major discomfort during such episodes. The pathophysiology of hot flashes is presumably related to the withdrawal of sex hormones resulting in a loss of negative feedback in $\beta$-endorphin and catecholestrogen production. Noradrenaline levels are increased in the hypothalamus, stimulating luteinizing hormone releasing hormone (LHRH) secreting neurons to secrete gonadotropins. Increased intrahypothalamic noradrenaline resets the LHRH 
neurons in the thermoregulatory center resulting in hot flashes (1 - 6). Although several studies on women with post-menopausal hot flashes have been reported, relatively few studies have investigated the frequency, severity and body temperature changes during hot flashes in men (2, 7 - 14).

The present study was triggered by a clinical question concerning a patient with advanced prostate cancer and renal cell cancer who underwent laparoscopic nephrectomy and simultaneous bilateral orchidectomy (BO). He developed a fever from day two post-surgery, for which no apparent reason could be found. The question arose whether core body temperature can be significantly elevated due to androgen deprivation within a day or two after BO. There was no obvious answer in the literature, therefore this study was undertaken to assess temperature changes after $\mathrm{BO}$ in men with prostate cancer.

\section{MATERIALS AND METHODS}

Patients who had undergone a BO for advanced prostate cancer were recruited for this study at the Urological Oncology Clinic of Tygerberg Hospital, Cape Town, South Africa. Study subjects were given a questionnaire to record the time period between $\mathrm{BO}$ and the onset of hot flashes, the number of hot flashes per day, the severity of the hot flashes (as judged by the patient on a scale of 2-10) and the duration of the hot flashes. They were also asked whether they were aware that hot flashes are the result of androgen deprivation.

A subgroup of patients was selected, who had to be literate and of sound mental status, and possess sufficient visual acuity to identify the markings on the temperature recording devices (Figure-1). They were provided with a notebook, electronic oral thermometer (measuring temperature in degrees Centigrade to two decimal points) and forehead temperature tape used clinically to measure temperature at $1^{\circ} \mathrm{C}$ intervals. The men were instructed on how to record their oral (core) and forehead (surface) temperatures at home during each episode when they experienced hot flashes and at fixed intervals between the hot flashes (at 08h00, 14h00 and 18h00) for a period of 4 weeks.
Statistical analysis was done by Student's ttest for parametric data, the Wilcoxon matched-pairs signed-ranks test for paired non-parametric data and the Mann-Whitney Test for unpaired non-parametric data.

\section{RESULTS}

In total, 101 consecutive patients were evaluated over the period of February 2004 to February 2005. A subgroup of 17 subjects was selected for temperature recordings according to the inclusion criteria. The mean (range) age of the patients was 71.6 (51 to 95) years in the whole group and 68.6 years (54 to 82$)$ in the subgroup. The mean follow up since BO was 33.2 months (median 29, range 2-90 months).

A total of 87 patients $(86 \%)$ reported hot flashes. Spontaneous remission had occurred in 9 (10\%) and $90 \%$ said that they were not aware of the fact that hot flashes are related to androgen deprivation. The characteristics of the hot flashes in the whole study group and in the subgroup are shown in Table1.

Detailed analysis of the temperature recordings in the subgroup of 17 patients showed no statistically significant difference between the median oral $\left(36.4^{\circ} \mathrm{C}\right)$ and forehead $\left(36.0^{\circ} \mathrm{C}\right)$ temperatures in the normal state (between hot flashes), but during hot flashes the median forehead temperature $\left(37.0^{\circ} \mathrm{C}\right)$ was significantly higher than the median oral temperature $\left(36.5^{\circ} \mathrm{C}\right)(\mathrm{p}=0.0004)($ Table-2). Both

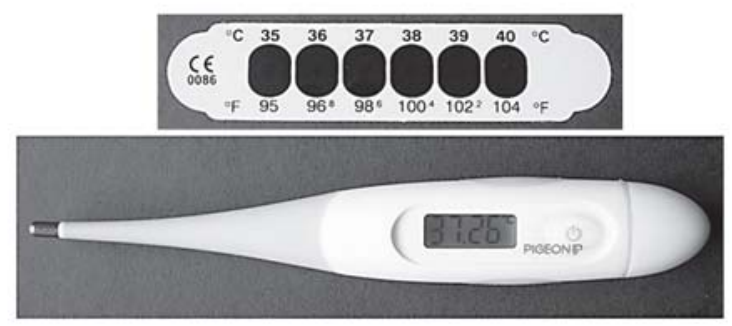

Figure 1 - Forehead temperature tape and electronic oral thermometer used in this study. 
Table 1 - Characteristics of hot flashes.

\begin{tabular}{lcc}
\hline & Whole Group $(\mathrm{N}=101)$ & Subgroup $(\mathrm{N}=17)$ \\
\hline Onset of hot flashes after BO (days) - median (range) & $21(1-730)$ & $14(1-90)$ \\
Frequency of hot flashes (per day) - median (range) & $3(1-20)$ & $5(1-15)$ \\
Severity of hot flashes - median (range) & $5.0(2-10)$ & $5.0(3-10)$ \\
Duration (seconds) - median (range) & $120(5-1800)$ & $120(15-900)$ \\
Severity of hot flashes (scale 2-10) & $\mathbf{N}(\boldsymbol{\%})$ & $\mathbf{N}(\boldsymbol{\%})$ \\
$\quad$ Mild (2-4) & $28(32.1)$ & $6(35.2)$ \\
$\quad$ Moderate (5-7) & $38(43.6)$ & $7(41.1)$ \\
$\quad$ Severe (8-10) & $21(24.1)$ & $4(23.5)$ \\
Duration of hot flashes & & \\
$>60$ seconds & $26(29.8)$ & $6(35.3)$ \\
$\quad 60-180$ seconds & $32(36.7)$ & $7(41.2)$ \\
$>180$ seconds & $29(33.3)$ & $4(23.5)$ \\
Frequency of hot flashes (per day) & & $8(47.1)$ \\
$1-4$ & $60(68.9)$ & $6(35.2)$ \\
$5-7$ & $20(22.9)$ & $3(17.6)$ \\
\hline 7 & $7(8.0)$ & \\
\hline
\end{tabular}

the median oral and forehead temperatures were statistically significantly higher during hot flashes $\left(36.5^{\circ}\right.$ $\mathrm{C}$ and $37.0^{\circ} \mathrm{C}$, respectively) than in the normal state $\left(36.4^{\circ} \mathrm{C}\right.$ and $36.0^{\circ} \mathrm{C}$, respectively) $(\mathrm{p}<0.0001)$ (Table2). However, in real terms these differences were small $\left(0.1^{\circ} \mathrm{C}\right.$ for the median oral and $1^{\circ} \mathrm{C}$ for the median forehead temperature).

During hot flashes the oral temperature was $38^{\circ} \mathrm{C}$ to $40^{\circ} \mathrm{C}$ in only $3.2 \%$ of 593 readings. The forehead temperature was $\geq 38^{\circ} \mathrm{C}$ in $20.8 \%$ of

Table 2 - Analysis of oral and forehead temperature recordings in 17 patients in the normal state and during hot flashes ( $n=$ number of readings).

\begin{tabular}{lcc}
\hline & $\begin{array}{c}\text { Oral Temperature }{ }^{\circ} \mathbf{C} \\
\text { median (range) }\end{array}$ & $\begin{array}{c}\text { Forehead Temperature }^{\circ} \mathbf{C} \\
\text { median (range) }\end{array}$ \\
\hline Normal (between hot flashes) & 36.4 & 36.0 \\
& $(33.4-38.3)$ & $(34.0-39.0)$ \\
& $\mathrm{N}=732$ & $\mathrm{~N}=732$ \\
During hot flashes & $(\mathrm{A})$ & $(\mathrm{B})$ \\
& 36.5 & 37.0 \\
& $(34.6-39.8)$ & $(34.0-40.0)$ \\
& $\mathrm{N}=593$ & $\mathrm{~N}=593$ \\
& $(\mathrm{C})$ & (D) \\
\hline
\end{tabular}

Wilcoxon matched-pairs signed-ranks test, two-tailed p-value: A vs. B: $p=0.53$ (not significant), Cvs. D: $p=0.0004$. Mann-Whitney test, two tailed p-value: A vs. C: $p<0.0001, B$ vs. D: $p<0.0001$. 
readings, but was $40^{\circ} \mathrm{C}$ in only $0.2 \%$ of readings (Table-3).

\section{COMMENTS}

McCullagh and Renshaw showed that vasomotor symptoms were the earliest effect of the hypogonadal state in patients treated for advanced prostate cancer, with these symptoms lasting for several years and gradually decreasing in frequency and intensity (15). Huggins and Hodges reported an incidence of $42.9 \%$ and postulated that patients not getting hot flashes may have an extragonadal source of androgens (16). Charig and Rundle found slightly elevated levels of testosterone in men not experiencing hot flashes (17).

Molnar assessed the body temperature differences in a single post-menopausal woman (7). The mean duration of hot flashes was 3.8 minutes (range 2.4 to $4.7 \mathrm{~min}$ ). The internal body temperature recorded from the rectum, vagina and tympanum fell after each hot flash. Surface temperatures recorded from the cheek, finger and toe showed an initial rise and then a slow fall. It was also noted that the surface temperature fell rapidly if hot flashes were associated with excessive perspiration (7).

Spetz et al. assessed plasma calcitonin generelated peptide, neuropeptide $\mathrm{Y}$, skin temperature and conductance in 10 patients on ADT (12). Their study showed a rise of $2.8^{\circ} \mathrm{C}$ in temperature recorded from the $3^{\text {rd }}$ finger dorsal surface, but no mention was made of normal temperature. This may be due to vasodilatation and increased blood flow during hot flashes, but there was no mention of how long the temperature rise persisted (12).

Frodin et al. measured the skin blood flow and water evaporation rate in patients with hot flashes and found that the evaporation rate increased more than $100 \%$ and cutaneous blood flow increased by $150 \%$ from baseline (8). Kronenberg et al. mentioned that the finger temperature can rise from $1^{\circ} \mathrm{C}$ to $7^{\circ} \mathrm{C}$ above baseline due to increased blood flow at the start of hot flashes (3).

The reported prevalence of hot flashes in men on androgen deprivation therapy for advanced prostate
Table 3 - Frequency distribution of oral and forehead temperature readings during hot flashes $(n=$ number of readings).

\begin{tabular}{|c|c|c|c|c|}
\hline \multirow{2}{*}{$\begin{array}{c}\text { Temperature } \\
\left({ }^{\circ} \mathrm{C}\right)\end{array}$} & \multicolumn{2}{|c|}{ Oral } & \multicolumn{2}{|c|}{ Forehead } \\
\hline & $\mathbf{N}$ & $\%$ & $\mathbf{N}$ & $\%$ \\
\hline 35 & 3 & 0.5 & 37 & 6.2 \\
\hline 35.5 & 18 & 3.0 & & \\
\hline 36 & 77 & 13.0 & 235 & 39.6 \\
\hline 36.5 & 221 & 37.3 & & \\
\hline 37 & 188 & 31.7 & 199 & 33.6 \\
\hline 37.5 & 67 & 11.3 & & \\
\hline 38 & 8 & 1.3 & 90 & 15.2 \\
\hline 38.5 & 6 & 1.0 & & \\
\hline 39 & 4 & 0.7 & 31 & 5.2 \\
\hline 39.5 & 0 & 0.0 & & \\
\hline 40 & 1 & 0.2 & 1 & 0.2 \\
\hline Total & 593 & 100 & 593 & 100 \\
\hline
\end{tabular}

cancer ranges from $30 \%$ to $80 \%$, with a remission rate of over $80 \%$ (9 - 13, 17 - 23). In our study of men after $\mathrm{BO}$, the incidence of hot flashes was $86 \%$ and the remission rate $10 \%$, which is lower than in studies of LHRHa where remission rates of $40 \%$ to $90 \%$ have been reported (19 - 24). One study of the long-term effect of BO in 75 patients showed an incidence of $76 \%$ for hot flashes, with a remission rate of $50 \%$ (17). Most of the flushers continued to have hot flashes until death or the end of study (follow-up 6 months to 4 years). The authors found slightly higher testosterone levels in non-flushers (17). The lower remission rate in our study could be the result of maintenance of lower testosterone levels, or the shorter duration of follow up than in other studies.

In studies of men on ADT, $10 \%$ of the patients had severe distress during hot flashes, while our study showed that $25 \%$ had severe distress. The higher incidence of severe hot flashes in our study could be due to the subjective nature of the assessment, or to lower levels of testosterone after BO compared to other forms of androgen deprivation. A shortcoming of this study is that we did not assess the testosterone or estrogen levels, but previous studies have shown that all patients reached castration levels of testosterone after BO $(9-12,19-25)$. 
At the time of study, the follow-up period after $\mathrm{BO}$ in our patients ranged from 2 to 90 months, with a mean follow up of 33.2 months. In total, $86 \%$ of our patients still had hot flashes at the time of study, which minimizes the risk of incorrect recall. The majority of our patients reported having $1-4$ hot flashes per day, maximum up to 20 . The duration of these flashes ranged from 5 to 1800 seconds, which corresponds to what has been reported in previous studies $(7,9,17,26)$.

In our study group the maximum oral temperature during hot flashes was $40^{\circ} \mathrm{C}$, but the oral temperature was $\geq 38^{\circ} \mathrm{C}$ in only $3.2 \%$ of 593 readings taken in 17 subjects. Therefore, in a patient with an oral temperature $\geq 38^{\circ} \mathrm{C}$ immediately after $\mathrm{BO}$, it is quite unlikely that the temperature elevation will be due to androgen deprivation.

In conclusion, our study showed that the great majority of men experience hot flashes after BO for prostate cancer, while the spontaneous remission rate is quite low. There is considerable variation in the time of onset, number, severity and duration of hot flashes. The mean core and surface body temperatures are statistically significantly higher during hot flashes than in normal periods between hot flashes, but in real terms these differences are small. In the clinical situation, a vasomotor response due to androgen deprivation is extremely unlikely to be the cause of a significant temperature elevation (in excess of $38^{\circ} \mathrm{C}$ ) within days after a $\mathrm{BO}$, therefore in such cases an alternative cause of the fever must be excluded.

\section{CONFLICT OF INTEREST}

None declared.

\section{REFERENCES}

1. Chakravarti S, Collins WP, Forecast JD, Newton JR, Oram DH, Studd JW: Hormonal profiles after the menopause. Br Med J. 1976; 2: 784-7.

2. Casper RF, Yen SS, Wilkes MM: Menopausal flushes: a neuroendocrine link with pulsatile luteinizing hormone secreation. Science. 1979; 205: 823-5.

3. Kronenberg F. Hot flashes: epidemiology and physiology. Ann N Y Acad Sci. 1990; 592:5 2-86.
4. Abdalla HI: Pathophysiology of hot flushes. Obstet Gynecol Surv. 1985; 40: 338-43.

5. Kouriefs C, Georgiou M, Ravi R: Hot flushes and prostate cancer: pathogenesis and treatment. BJU Int. 2002; 89:379-83.

6. Stearns V, Ullmer L, Lopez JF, Smith Y, Isaacs C, Hayes D: Hot flushes. Lancet. 2002; 360: 1851-61.

7. Molnar GW: Body temperatures during menopausal hot flashes. J Appl Physiol. 1975; 38: 499-503.

8. Frodin T, Alund G, Varenhorst E: Measurement of skin blood-flow and water evaporation as a means of objectively assessing hot flushes after orchidectomy in patients with prostatic cancer. Prostate. 1985; 7: 2038.

9. Karling P, Hammar M, Varenhorst E: Prevalence and duration of hot flushes after surgical or medical castration in men with prostatic carcinoma. J Urol. 1994; 152: 1170-3.

10. Schow DA, Renfer LG, Rozanski TA, Thompson IM: Prevalence of hot flushes during and after neoadjuvant hormonal therapy for localized prostate cancer. South Med J. 1998; 91: 855-7.

11. Spetz AC, Hammar M, Lindberg B, Spangberg A, Varenhorst E; Scandinavian Prostatic Cancer Group-5 Trial Study: Prospective evaluation of hot flashes during treatment with parenteral estrogen or complete androgen ablation for metastatic carcinoma of the prostate. J Urol. 2001; 166: 517-20.

12. Spetz AC, Pettersson B, Varenhorst E, Theodorsson E, Thorell LH, Hammar M: Momentary increase in plasma calcitonin gene-related peptide is involved in hot flashes in men treated with castration for carcinoma of the prostate. J Urol. 2001; 166: 1720-3.

13. Suzuki K, Kobayashi M, Tokue A: Clinical evaluation of hot flushes developing during endocrine therapy for prostate carcinoma. Nippon Hinyokika Gakkai Zasshi. 2003; 94: 614-20.

14. Nishiyama T, Kanazawa S, Watanabe R, Terunuma M, Takahashi K: Influence of hot flashes on quality of life in patients with prostate cancer treated with androgen deprivation therapy. Int J Urol. 2004; 11: 735-41.

15. McCullagh EP, Renshaw JF: The effects of castration on the adult male. JAMA. 1934; 103: 1140-3.

16. Huggins C, Hodges C. Studies on prostatic cancer 1: the effect of castration, of estrogen and androgen injection on serum phosphatases in metastatic carcinoma of the prostate. Cancer Res. 1941; 1: 293-7.

17. Charig CR, Rundle JS: Flushing. Long-term side effect of orchiectomy in treatment of prostatic carcinoma. Urology. 1989; 33: 175-8. 
18. Koutsilieris M, Faure N, Tolis G, Laroche B, Robert G, Ackman CF: Objective response and disease outcome in 59 patients with stage D2 prostatic cancer treated with either Buserelin or orchiectomy. Disease aggressivity and its association with response and outcome. Urology. 1986; 27: 221-8.

19. Sharifi R, Knoll LD, Smith J, Kramolowsky E: Leuprolide acetate (30-mg depot every four months) in the treatment of advanced prostate cancer. Urology. 1998; 51:271-6.

20. Fernandez del Moral P, Dijkman GA, Debruyne FM, Witjes WP, Kolvenbag GJ: Three-month depot of goserelin acetate: clinical efficacy and endocrine profile. Dutch South East Cooperative Urological Group. Urology. 1996; 48: 894-900.

21. Nyman CR, Andersen JT, Lodding P, Sandin T, Varenhorst E: The patient's choice of androgendeprivation therapy in locally advanced prostate cancer: bicalutamide, a gonadotrophin-releasing hormone analogue or orchidectomy. BJU Int. 2005; 96: 1014-8.
22. Eisenberger MA, Blumenstein BA, Crawford ED, Miller G, McLeod DG, Loehrer PJ, et al.: Bilateral orchiectomy with or without flutamide for metastatic prostate cancer. N Engl J Med. 1998; 339: 1036-42.

23. The Leuprolide Study Group: Leuprolide versus diethylstilbestrol for metastatic prostate cancer. . N Engl J Med. 1984; 311: 1281-6.

24. Metz R, Namer M, Adenis L, Audhuy B, Bugat R, Colombel P, et al.: Zoladex as primary therapy in advanced prostatic cancer. A French cooperative trial. Am J Clin Oncol. 1988; 11 (Suppl 2): S 112-4.

25. Iversen P, Tyrrell CJ, Kaisary AV, Anderson JB, Van Poppel H, Tammela TL, et al.: Bicalutamide monotherapy compared with castration in patients with nonmetastatic locally advanced prostate cancer: 6.3 years of follow up. J Urol. 2000; 164: 1579-82.

26. Langenstroer P, Kramer B, Cutting B, Amling C, Poultan T, Lance R, et al.: Parenteral medroxyprogesterone for the management of luteinizing hormone releasing hormone induced hot flashes in men with advanced prostate cancer. J Urol. 2005; 174: 642-5.

Accepted after revision:

September 30, 2007

\section{Correspondence address:}

Dr. C. F. Heyns

Department of Urology

POBox 19063

Tygerberg, 7505, South Africa

Fax:+2721 933-8010

E-mail: cfh2@sun.ac.za

\section{EDITORIAL COMMENT}

Androgen-depriviation therapy (ADT) for managing prostate cancer has become increasingly popular. With the increasing indications for the use of ADT for prostate cancer, side effects such as hot flashes (HF), decreased libido and decreased sexual function deserve greater attention. Within the side effects, it has been reported that $68 \%$ of the patients had HFs during treatment with medical or surgical castration, and that symptoms generally do not subside with time on treatment, with $48 \%$ of men experiencing 
symptoms at 5 years and $40 \%$ of men continuing to experience symptoms at 8 years (1). Exposure to ADT and its side effects is lengthy, and because it is palliative, side effects must be addressed and treated effectively. Although HF is not a serious adverse effect, when it becomes severe and frequent it can be very annoying to the patient, and interfere with the patient's quality of life, and some prostate cancer patients have considered discontinuing ADT. Pathophysiology underlying HF induced by ADT is not entirely clear. This report can be one of the clues for understanding the mechanisms of HF.

\section{REFERENCE}

1. Karling P, Hammar M, Varenhorst E: Prevalence and duration of hot flushes after surgical or medical castration in men with prostatic carcinoma. J Urol. 1994; 152: 1170-3.

\author{
Dr. Michio Naoe \\ Department of Urology \\ Showa University \\ Tokyo, Japan \\ E-mail:naoe@east.cts.ne.jp
}

\section{EDITORIAL COMMENT}

Bilateral orchiectomy was first used by Huggins and Hodges in 1941 (1) and is considered the "gold standard" of endocrine treatment for advanced prostate cancer. It is a simple procedure with a very low rate of surgical complications that can be performed in out patient setting under local anesthesia. The serum testosterone level reduces to nadir levels within 12-24 hours after orchiectomy (2). The hot flushes usually begin 2-3 weeks after surgery (3), affecting roughly $40-60 \%$ of patients (4).

The main endpoint of this manuscript was to assess body temperature changes during hot flashes in men after bilateral orchiectomy for prostate cancer. Out of 101 patients included in the study, the body temperature changes during hot flushes has been evaluated in a group of only 17 patients, too small to draw definitive conclusions. Despite this, one message that we can take from this paper is to remember that temperatures greater than $38^{\circ} \mathrm{C}$ seem unlikely to be result of androgen deprivation alone, even if this aspect has not been extensively investigated.

The analysis of the incidence and principally the severity of hot flushes in this paper have relied on the use of subjective and not validated tools. Maybe the use of the Hot Flash Related Daily Interference Scales (HFRDIS) (3), developed for assessing the impact of hot flashes on quality of life in breast cancer patients, should be considered to provide more precise information about these patients (5).

Finally, it is a matter of concern that $90 \%$ of the patients recruited were not aware of the fact that hot flashes were related to androgen deprivation; this important point shows the not negligible role of the communication between patients and physicians prior to such therapies.

\section{REFERENCES}

1. Huggins C, Hodges CV: Studies on prostatic cancer. I. The effect of castration, estrogen and androgen injection on serum phosphatases in metastatic carcinoma of the prostate. Cancer Res. 1941; 1: 293-7.

2. Maatman TJ, Gupta MK, Montie JE: Effectiveness of castration versus intravenous estrogen therapy in producing rapid endocrine control of metastatic cancer of the prostate. J Urol. 1985; 133: 620-1. 
3. Carpenter JS: The Hot Flash Related Daily Interference Scale: a tool for assessing the impact of hot flashes on quality of life following breast cancer. J Pain Symptom Manage. 2001; 22: 979-89.
4. Kouriefs C, Georgiou M, Ravi R: Hot flushes and prostate cancer: pathogenesis and treatment. BJU Int. 2002; 89: 379-83.

5. Kattan MW: Measuring hot flashes in men treated with hormone ablation therapy: an unmet need. Urol Nurs. 2006; 26: 13-8.

\section{EDITORIAL COMMENT}

The authors are to be congratulated for identifying a concise clinical question and answering it with a small clinical research project. That question is stated as follows: can an unexplained fever on postoperative day two following bilateral orchiectomy be due to hot flashes? Using only 17 selected patients for temperature measurements and a brief literature review, the authors have answered the question with a "no". The clinical applicability of this answer is minimal however. No surgeon will change his or her work-up of postoperative fever even if the answer was "yes." This paper briefly mentions prior work regarding biochemical mechanisms of hot flashes, but contributes nothing to further understanding in this area. The authors briefly mention possible differences between bilateral orchiectomy and medical castration that, if true, further weaken the applicability of their selected patient population to current clinical practice. Nevertheless, this work serves as a reminder that for non-curative therapies, such as androgen deprivation, greater emphasis must be placed on minimizing sideeffects. Future research into the biochemical aspects of hot flashes will hopefully allow amelioration of not only these, but other side-effects of androgen deprivation including osteoporosis, loss of libido or impotence, and psychological effects.

\author{
Dr. Eric C. Nelson \& \\ Dr. Christopher P. Evans \\ Department of Urology \\ Univ. of California, Davis, School of Medicine \\ Sacramento, California, USA \\ E-mail: enelson06m@gmail.com
}

